\title{
Load Frequency Control of Two-Area Smart Grid
}

\author{
K. Saiteja \\ Electrical \& Electronics Engineering Dept. \\ V R Siddhartha Engineering College Vijayawada, \\ India 520007
}

\author{
M.S. Krishnarayalu \\ Electrical \& Electronics Engineering Dept. \\ V R Siddhartha Engineering College Vijayawada, \\ India 520007
}

\begin{abstract}
Nowadays electrical load demand is increasing day by day. Conventional grids alone cannot meet the increasing load demands as their generation is limited by natural resources like coal, water etc. This results in frequency problems. Even the existing Load Frequency Controllers may not solve this problem. This resulted in Smart Grids with renewable generation like wind, solar etc. and plug- in hybrid electric vehicle (PHEV) which can supply the increased load demand from different energy sources. Smart grids are a reality which require good controllers. Hence different controllers like Ziegler-Nichols tuned PID,PSO tuned PID, MATLAB tuned PID and ADRC controllers are tested for a two-area smart grid with PHEV and wind generation through simulations.
\end{abstract}

\section{General Terms}

Voltage, frequency, power

\section{Keywords}

Load frequency control, Smart grid, Plug-in hybrid electric vehicle, Vehicle-to-grid control, Battery state-of-charge, Particle swarm optimization, PID controller, Active disturbance rejection controller.

\section{INTRODUCTION}

Load Frequency Control (LFC) problem in the power system operation and control has a long history [1-4]. LFC is one of the most important and recent topics of research in interconnected power systems [5]. The generators in a control area always vary their speed together (speed up or slow down) for maintaining the frequency and the relative power angles to the predefined values with tolerance limit in both static and dynamic conditions. If any sudden change in load occurs in any control area of an interconnected power system then there will be frequency deviation as well as tie line power deviation. Frequency should remain constant at rated value for satisfactory operation of power system. Frequency deviations can directly impact a power system operation, reliability and efficiency. Large frequency deviations can damage equipment, degrade load performance, overload transmission lines and affect the performance of system protection schemes. These large frequency deviation events can ultimately lead to a system collapse. Variation in frequency adversely affects the operation and speed control of induction and synchronous motors. In domestic arena, refrigerator's efficiency goes down; television and air conditioners reactive power consumption increases considerably with reduction in power supply frequency. Hence it is very important to maintain the frequency at rated value or within acceptable range. Due to the dynamic nature of the load, continuous load change cannot be avoided but the system frequency can be kept within sufficiently small tolerance levels by adjusting the generation continuously. A good LFC system maintains the control area frequency and tie line power at their nominal and scheduled values [2-5].
Power system security and reliability are becoming major concern due to the increasing complexity of power system operation. Smart grid usage makes the grid more secure and reliable due to the intelligence added via advanced information technology [6]. With the development of renewable energy coming from such resources as sun and wind, the number of distributed generations increased dramatically. Due to the unpredictable nature of these renewable energy sources, especially wind energy, a good number of energy storage systems is highly desirable to make such resources dependable. With the distributed generation and energy storage system being connected to the power grid, power network structure becomes more complex. The complex power system becomes more difficult to control.

To reduce the global climate change and to enhance the energy security, new technologies that reduce the $\mathrm{CO}_{2}$ emissions have been investigated for some years. The interest in battery electric vehicles (BEVs) and plug-in hybrid electric vehicles (PHEVs) has increased due to their ability to reduce the $\mathrm{CO}_{2}$ pollution, low-cost charging, and reduced petroleum usages. Compared with traditional hybrid electric vehicles (HEVs), BEVs/PHEVs have an enlarged battery pack and an intelligent converter. Using a plug, BEVs/PHEVs can charge the battery using electricity from an electric power grid, which is called as "grid-to-vehicle" (G2V) operation. Similarly discharge of these vehicles to an electric power grid, during the parking hours, is referred to as "vehicle-to-grid" (V2G) operation. Many researchers have investigated the various potential benefits and implementation issues of V2G [7-10].

The V2G control, based on the average battery State Of Charge (SOC) deviation control, is applied to compensate the LFC capacity in the power system. Reference [11] concentrates on the autonomous distributed $\mathrm{V} 2 \mathrm{G}$ control considering the charging request and battery condition for reducing the fluctuations of frequency and tie-line power flow in the two-area interconnected power system. The battery SOC is controlled by the SOC balance method. In addition, the smart charging control technique is proposed for satisfying the scheduled charging by the vehicle user [12]. However, the $\mathrm{V} 2 \mathrm{G}$ control and frequency controller parameters in $[11,12]$ are separately determined for each area. Hence they cannot guarantee the well-coordinated control effects of V2G and frequency controllers.

Particle Swarm Optimization (PSO) algorithm is an optimization method that finds the best parameters for controller in the uncertainty area of controller parameters and results in an optimal controller. It has been used in many sectors of industry and science. One of those areas is the load frequency control [13].

PID controller is the most established controller in industry. It is error activated and very simple to implement. It improves both transient and steady state performances. The Active Disturbance Rejection Controller (ADRC) is a novel robust 
approach [14-18]. ADRC improvises the PID controller. The ADRC controller is also being applied in many areas such as aerospace, aviation, electricity, chemical industry and other fields. Some of its merits are disturbance rejection, simple algorithm, small settling time and little overshoot.

An extended state observer (ESO) that estimates disturbance (internal plus external) $d(t)$ present, is the heart of ADRC. Later this estimation will be used to eliminate the impact of $\mathrm{d}(t)$. All that remains to be handled by the actual controller is a process with approximately integrating behavior which can be accomplished easily by a simple proportional controller.

This paper presents a coordinated V2G control and a robust frequency controller (ADRC) for LFC in an interconnected power system with PHEVs and large wind farms. The battery SOC is managed by controlling the optimized SOC deviation based on the balanced SOC control. Simulation studies present the coordinated control effects of the proposed V2G control with PID controller tuned by Ziegler-Nichols, PSO, MATLAB methods and ADRC controller.

\section{SYSTEM MODELING}

Fig. 1 shows a smart multi-area interconnected power system with large wind power generation. The V2G-based PHEVs are applied to compensate the unequal real powers in each area when the LFC capacity is not enough. A two-area interconnected power system with large wind farms and PHEVs is considered for the simulation study. Here each area consists of the wind power, thermal power, LFC, PHEV and load.

Due to the sudden power change from the intermittent wind power and the load fluctuation, the thermal generator may not compensate sufficiently the power because of its slow dynamic response. The fast dynamic response of vehicle battery based multiple PHEVs will compensate the real power unbalance in the system when the LFC capacity is inadequate. The dynamic response of the PHEV is faster than the turbine and governor of thermal generator. Consequently, the operational tasks are assigned according to the response speed as follows. The PHEV is responsible for damping the peak value of frequency oscillation rapidly. Subsequently, the turbine and governor of thermal generator are utilized for eliminating the steady state error of frequency fluctuation. A SIMULINK model of the smart two-area interconnected power system is shown in Fig. 2. Please note subsystems are shown for Area 1 only. Similar subsystems are there for Area 2 also based on data [11] given in Tables 1 and 2 .

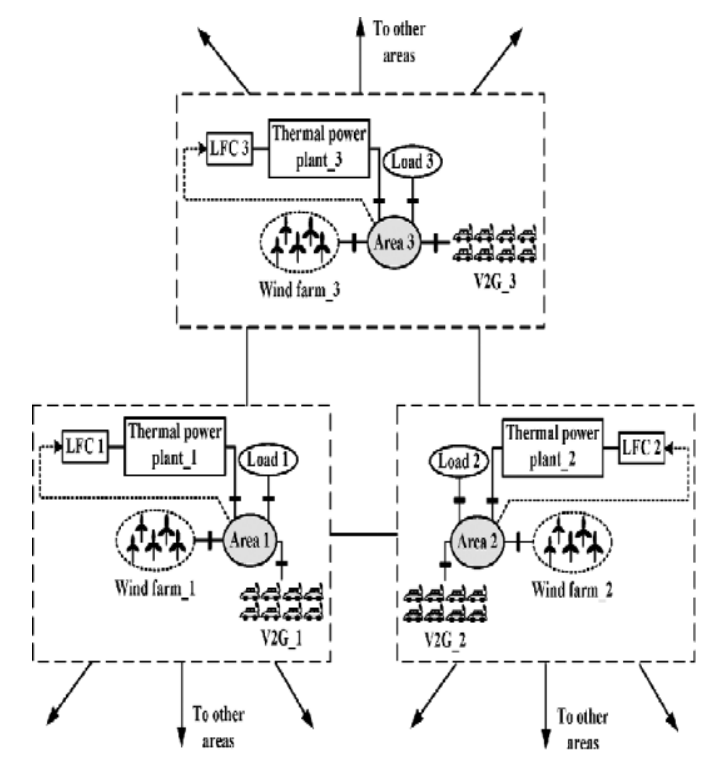

Fig. 1. A smart multi-area interconnected power system.

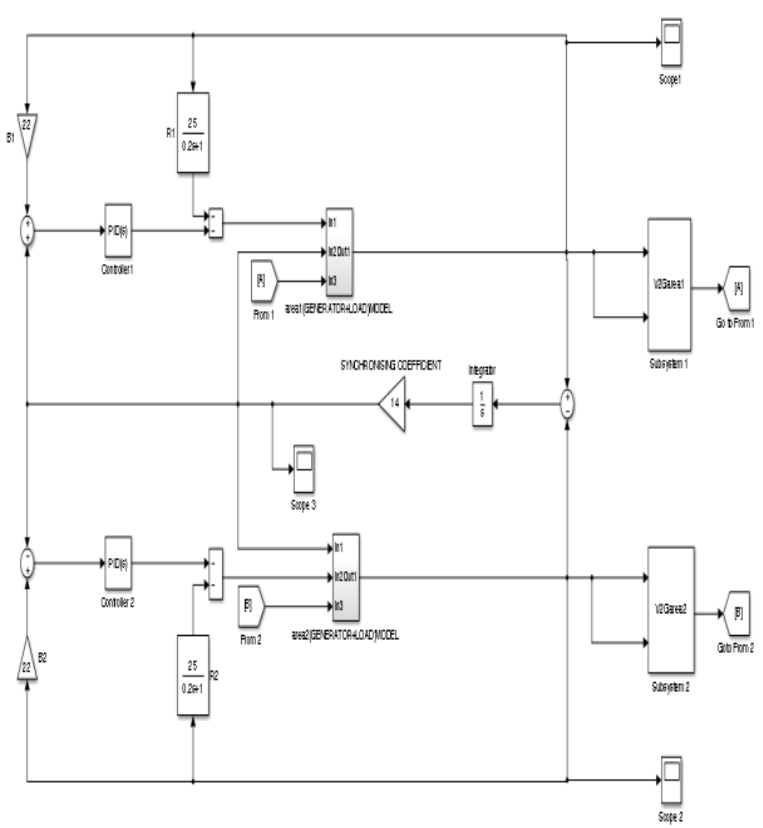

Fig. 2. SIMULINK model of two area smart grid

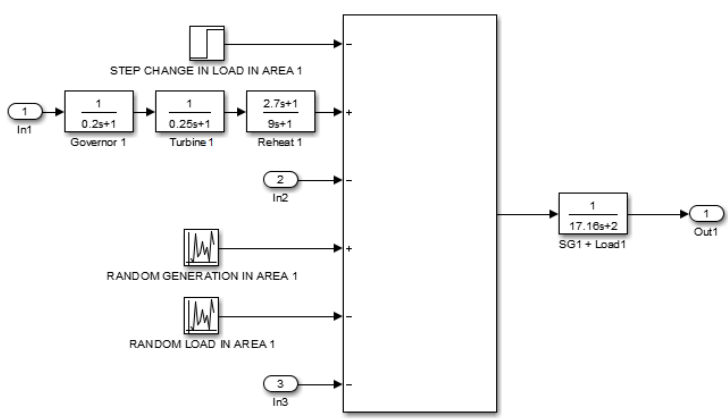

Fig. 2a Subsystem of Primary Loop with different generations of Area1 


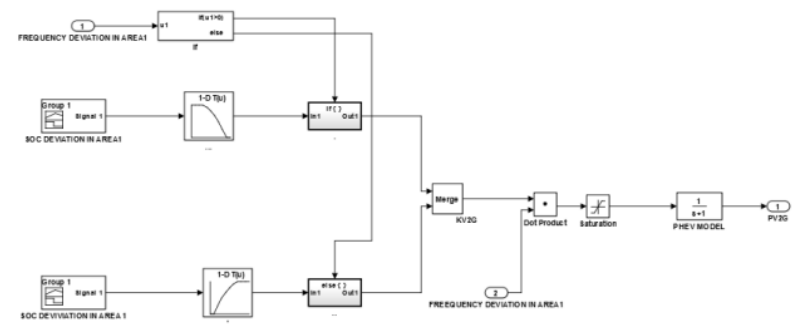

Fig. 2b Subsystem of V2G Model of Area1

Table 1: LFC data in areas 1 and 2

\begin{tabular}{|l|c|c|}
\hline Parameter & Area 1 & Area 2 \\
\hline Load capacity, $\mathrm{P}_{\mathrm{L}}(\mathrm{MW})$ & 33090 & 7090 \\
\hline $\begin{array}{l}\text { Rated thermal power output, } \mathrm{P}_{\mathrm{O}} \\
\text { (MW) }\end{array}$ & 24252 & 5560 \\
\hline Inertia constant, H sec & 8.58 & 9.02 \\
\hline $\begin{array}{l}\text { Load damping coefficient, } \\
\text { D (p.u.MW/p,u.Hz) }\end{array}$ & 0.25 & 2 \\
\hline Turbine time constant, Tt (sec) & 0.2 & 0.2 \\
\hline Governor time constant, Tg (sec) & 9 & 9 \\
\hline Re-heat time constant, Trh (sec) & 0.05 & 0.05 \\
\hline Governor speed regulation, R (p.u.) & 14 & 14 \\
\hline $\begin{array}{l}\text { Synchronizing coefficient, } \\
\text { (p.u./rad) }\end{array}$ & 0.2 & 0.1 \\
\hline Load change, $\Delta P_{L}$ (p.u.) & $-1.1 \sim 2$ & $-1.1 \sim 2$ \\
\hline Random Generation Range (p.u.) & $-0.9 \sim 0.8$ & $-0.9 \sim 0.8$ \\
\hline Random Load Range (p.u.) & & \\
\hline
\end{tabular}

Table 2: V2G control data in areas 1 and 2

\begin{tabular}{|c|c|c|}
\hline Parameter & Area 1 & Area 2 \\
\hline Maximum V2G Power, Pmax (kw) & 5 & 5 \\
\hline $\begin{array}{llll}\begin{array}{l}\text { Maximum } \\
(\mathrm{kw} / \mathrm{Hz})\end{array} & \text { V2G } \text { Gain, Kmax } \\
\end{array}$ & 200 & 200 \\
\hline Design parameter: $\mathrm{n}$ & 2 & 2 \\
\hline $\mathrm{SOC}_{\min }(\%)$ & 10 & 10 \\
\hline $\mathrm{SOC}_{\text {low }}(\%)$ & 20 & 20 \\
\hline $\mathrm{SOC}_{\text {high }}(\%)$ & 80 & 80 \\
\hline $\mathrm{SOC}_{\max }(\%)$ & 90 & 90 \\
\hline Initial SOC(\%),Target SOC(\%) & 20,90 & 50,50 \\
\hline Delay time, $\mathrm{T}_{\mathrm{PHEV}}(\mathrm{sec})$ & 1 & 1 \\
\hline
\end{tabular}

\section{V2G POWER CONTROL}

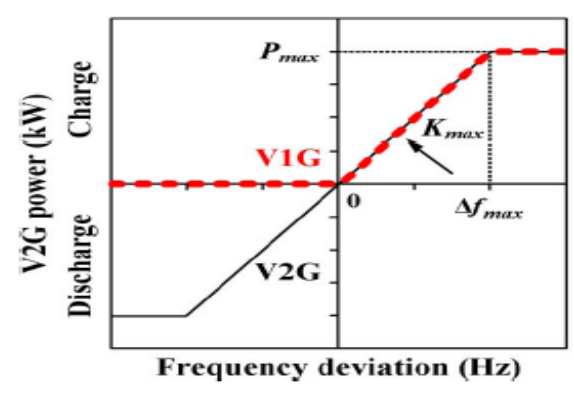

Fig. 3.V2G power control

The V2G power and SOC deviation controls [11] are described as follows.

\subsection{V2G Power Control}

Supply and demand imbalance of the power grid can be observed from the frequency deviation detected at home outlet [7]-[12]. Therefore $\mathrm{V} 2 \mathrm{G}$ power $\left(\mathrm{P}_{\mathrm{V} 2 \mathrm{G}}\right)$ is controlled with droop characteristics against the frequency deviation $(\Delta \mathrm{f})$ as shown in Fig.3.

$P_{V 2 G}= \begin{cases}K_{V 2 G} \Delta f & \left(\left|K_{V 2 G} \Delta f\right| \leq P_{\max }\right) \\ P_{\max } & \left(P_{\max }<\left|K_{V 2 G} \Delta f\right|\right)\end{cases}$

where $\mathrm{K}_{\mathrm{V} 2 \mathrm{G}}$ is the $\mathrm{V} 2 \mathrm{G}$ gain tuned by taking a tradeoff between the $\mathrm{V} 2 \mathrm{G}$ effect and the battery SOC deviation range into consideration. $\mathrm{P}_{\max }$ is the maximum $\mathrm{V} 2 \mathrm{G}$ power defined by the $200 \mathrm{~V} / 25 \mathrm{~A}$ home outlet. When the SOC is near to full (empty), a high-power charging (discharging) should not be implemented for preventing overcharge (over discharge). During long-term V2G cycles, the SOC is concerned to be full or empty because a mean value of the frequency deviation is not always zero and there is a loss of the battery. Considering these features, a balance control is installed as the following equation on the basis that the accurate SOC estimation is realized [11]:

$K_{V 2 G}=K_{\max }\left\{1-\left(\frac{S O C-S O C_{\text {low (high })}}{S O C_{\max (\min )}-S O C_{\text {low }(\text { high })}}\right)^{n}\right\}$

where $\mathrm{K}_{\max }$ is maximum $\mathrm{V} 2 \mathrm{G}$ gain. $\mathrm{SOC}_{\min }, \mathrm{SOC}_{\text {low }}, \mathrm{SOC}_{\text {high }}$, $\mathrm{SOC}_{\max }$ and $\mathrm{n}$ are the minimum battery SOC, low battery SOC, high battery SOC, maximum battery SOC and design parameter respectively.

\subsection{SOC Deviation Control}

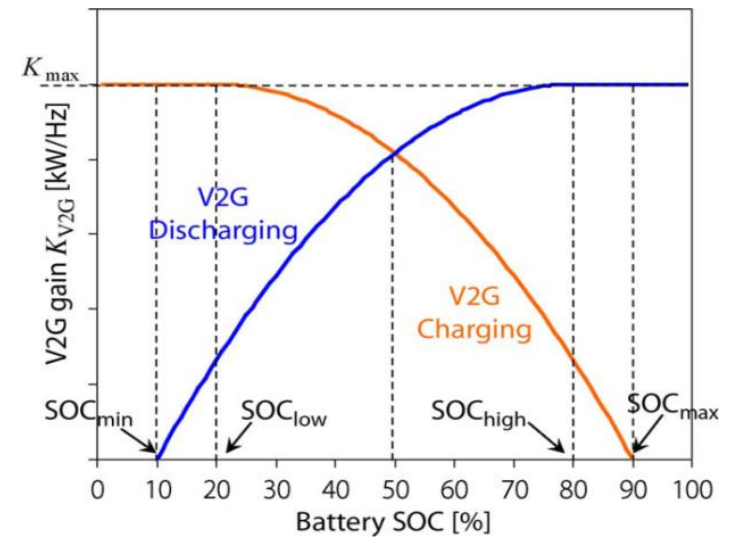

Fig. 4 SOC Balance Control 
The SOC can be controlled by the SOC balance control as shown in Fig. 4. Based on (1) and (2), $\mathrm{P}_{\mathrm{V} 2 \mathrm{G}}$ can be controlled by tuning the gain $\mathrm{K}_{\mathrm{V} 2 \mathrm{G}}$ against the frequency deviation. $\mathrm{K}_{\mathrm{V} 2 \mathrm{G}}$ can be adjusted by the SOC deviation control within the specified SOC range. Here, the initial SOC and target SOC in area 1 are set at $20 \%$ and $90 \%$, respectively. Also, in area 2, the initial SOC and target SOC are set at 50\% and 50\%, respectively.

\section{CONTROLLERS}

PID and ADRC controllers are employed as secondary controllers for the LFC problem. PID controller is tuned by a number of methods as given below.

\subsection{PID Controller Tuning}

The basic structure of a PID controller is

$$
\mathrm{G}_{\mathrm{c}}(\mathrm{s})=\mathrm{K}_{\mathrm{P}}+\mathrm{K}_{\mathrm{I}} / \mathrm{s}+\mathrm{K}_{\mathrm{D}} \mathrm{s}
$$

where $K_{P}, K_{I}$ and $K_{D}$ are proportional, integral and derivative gain constants. Proportional control results in decrease of rise time but also results in oscillatory performance. Derivative control reduces the oscillations by providing proper damping which results in improved transient performance and stability. Integral control reduces the steady state error to zero. Theoretically $\mathrm{K}_{\mathrm{P}}, \mathrm{K}_{\mathrm{I}}$ and $\mathrm{K}_{\mathrm{D}}$ are to be selected from infinite combinations. Proper selection $\mathrm{K}_{\mathrm{P}}, \mathrm{K}_{\mathrm{I}}$ and $\mathrm{K}_{\mathrm{D}}$ is the tuning of PID controller.

\subsubsection{Ziegler-Nichols (Z-N) Method}

In 1942 Ziegler and Nichols, who were engineers for a major control hardware company in the United States (Taylor Instruments Co), proposed tuning rules for the "Optimum settings for automatic controllers". Based on their experience with transients for many types of processes they developed a method for tuning of closed-loop response. The principal control effects found in PID-controller were examined and practical names and units proposed for each effect. They suggested that ultimate controller gain $\mathrm{K}_{\mathrm{U}}$, and ultimate period $\mathrm{P}_{\mathrm{U}}$, were to be obtained from a closed-loop test of the actual process. When the process is in steady state within the normal level of operating, the integral and the derivative modes of the PID-controller are removed leaving only the proportional control. On some controllers, this might require setting the deviate time to its minimal value and the integrating time to its maximum value. Disturb the system by adding an increasing value of proportional gain to the controller, until the system response with a sustained constant oscillating output. The corresponding $\mathrm{K}_{\mathrm{U}}$ is denoted as the ultimate gain, and the period of oscillation is the ultimate period, $\mathrm{P}_{\mathrm{U}}$. The $\mathrm{Z}-$ $\mathrm{N}$ tuning rules [20], given in Table 3, are then used to set the controller parameters for a Proportional (P), a Proportionalintegral (PI) or a Proportional-integral-derivative (PID) controller. This Z-N method is very simple to implement.

Table 3: Z-N Tuning Method

\begin{tabular}{|l|c|c|c|}
\hline Type of Controller & $\mathrm{K}_{\mathrm{P}}$ & $\mathrm{T}_{\mathrm{I}}$ & $\mathrm{T}_{\mathrm{D}}$ \\
\hline Proportional (P) & $0.5 * \mathrm{~K}_{\mathrm{U}}$ & $\infty$ & 0 \\
\hline Proportional-integral (PI) & $0.45 * \mathrm{~K}_{\mathrm{U}}$ & $\frac{P_{U}}{1.2}$ & 0 \\
\hline $\begin{array}{l}\text { Proportional-integral-derivative } \\
\text { (PID) }\end{array}$ & $0.6 * \mathrm{~K}_{\mathrm{U}}$ & $\frac{P_{U}}{2}$ & $\frac{P_{U}}{8}$ \\
\hline
\end{tabular}

\subsubsection{PSO Tuned PID}

Particle swarm optimization (PSO) is an evolutionary computation technique developed by Dr. Eberhart and Dr. Kennedy in 1995, inspired by social behavior of bird flocking or fish schooling. PSO is a population based optimization tool. The system is initialized with a population of random solutions and searches for optima by updating generations. All the particles have fitness values, which are evaluated by the fitness function to be optimized, and have velocities, which direct the flying of the particles. All particles fly through a multidimensional search space where each particle is adjusting its position according to its own experience and neighbor's experience. Each particle keeps track of its coordinates in the solution space which are associated with the best solution (fitness) that has achieved so far by that particle. This value is called personal best, pbest. Another best value that is tracked by the PSO is the best value obtained so far by any particle in the neighborhood of that particle. This value is called gbest. The basic concept of PSO lies in accelerating each particle toward its pbest and the gbest locations, with a random weighted acceleration at each time step. Detailed algorithm is available in [13].

The objective function, $\mathrm{J}$ for PSO is taken as to minimize the frequency deviations in areas 1 and 2 as:

$\mathrm{J}=\int_{0}^{\infty}\left|\Delta f_{1}\right| d t+\int_{0}^{\infty}\left|\Delta f_{2}\right| d t$

Subject to

$$
\begin{aligned}
K_{P 1-2, \min } & <K_{P 1-2}<K_{P 1-2, \text { max }} \\
K_{I 1-2, \min } & <K_{I 1-2}<K_{I 1-2, \text { max }} \\
K_{D 1-2, \text { min }} & <K_{D 1-2}<K_{D 1-2, \text { max }}
\end{aligned}
$$

\subsubsection{MATLAB Tuned PID}

In MATLAB, the transfer function of PID controller is

$G_{C}(\mathrm{~s})=K_{P}+\frac{K_{I}}{s}+\left\{K_{D} N s /(\mathrm{s}+\mathrm{N})\right\}$

where $\mathrm{N}$ sets the pole location of derivative noise filter. Default value of $\mathrm{N}$ is 100.PID controller tuning can be achieved in three steps using MATLAB SIMULINK [19]. In Step 1 select $K_{P}$ that results in a highly oscillatory stable response with $K_{D}=K_{I}=0$. In Step 2 fix the parameter $K_{D}$, for $\mathrm{K}_{\mathrm{P}}$ selected in Step1, to take care of transient performance. In Step 3 acquire the parameter $K_{I}$, for $K_{P}$ and $K_{D}$ selected in Steps 1 and 2, to take care of steady state performance. Actually this selection converges to a set of values of $\mathrm{K}_{\mathrm{P}}, \mathrm{K}_{\mathrm{I}}$ and $\mathrm{K}_{\mathrm{D}}$. This completes the tuning of PID controller.

Following the above tuning methods the resulting parameters of PID controller are given in Table 4.

Table 4: PID tuning results

\begin{tabular}{|l|l|l|l|l|l|l|}
\hline \multirow{2}{*}{ Method } & \multicolumn{3}{|c|}{ Area 1 } & \multicolumn{3}{c|}{ Area 2 } \\
\cline { 2 - 7 } & $\mathrm{K}_{\mathrm{P}}$ & $\mathrm{K}_{\mathrm{I}}$ & $\mathrm{K}_{\mathrm{D}}$ & $\mathrm{K}_{\mathrm{P}}$ & $\mathrm{K}_{\mathrm{I}}$ & $\mathrm{K}_{\mathrm{D}}$ \\
\hline Z-N & 3.307 & 2.755 & 1.6 & 3.307 & 2.755 & 1.6 \\
\hline PSO & 4.932 & 0.965 & 2.7636 & 11 & 1.4 & 3.5 \\
\hline MATLAB & 9.5 & 4.956 & 4.5 & 13 & 1.8 & 5.5 \\
\hline
\end{tabular}

\subsection{ADRC Design [17, 18]}

Here an $(n+1)$ th-order ESO is used to estimate the $n$ states and disturbance (internal and external) in order to eliminate the disturbance. The resulting system acts as an nth order integrator 


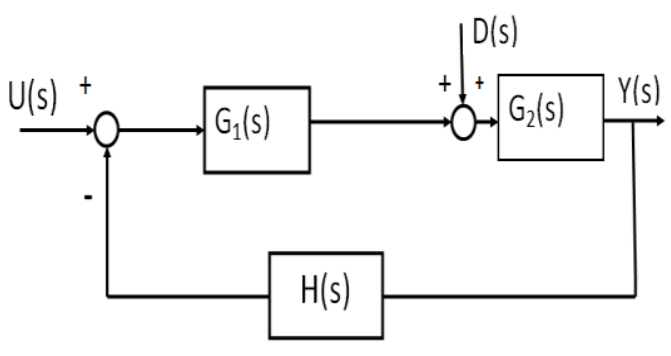

Fig 5. Block Diagram of primary loop

\section{STEP 1: Plant Remodeling}

The design strategy of ADRC is presented for a general nth order transfer function model of a physical system with primary loop as shown in Fig 5.General form of plant with finite zeros represented by a minimum phase transfer function is

$G_{p}(s)=\frac{Y(s)}{U(s)}=\frac{b_{m+1} s^{m}+b_{m} s^{m-1}+\ldots+b_{2} s+b_{1}}{a_{n+1} s^{n}+a_{n} s^{n-1}+\ldots .+a_{2} s+a_{1}}, n \geq m$

where $\mathrm{U}(\mathrm{s})$ and $\mathrm{Y}(\mathrm{s})$ are input and output of the plant respectively. $\quad a_{i}$ and $b_{j}(i=1,2, \ldots, n+1 ; j=1,2, \ldots, m+$ $1)$ are the coefficients of the transfer function. After performing the longhand division of (6), the plant model may be shown as

$s^{\mathrm{n}-\mathrm{m}} \mathrm{Y}(\mathrm{s})=\mathrm{b}_{0} \mathrm{U}(\mathrm{s})+\mathrm{D}(\mathrm{s})$

with $b_{0}=b_{m+1} / a_{n+1}$. $D(s)$ includes both internal and external disturbances. After remodeling, the plant has two important characteristics. One is the order of the remodeled plant $(=n-$ $\mathrm{m}$ ) and the other is the high frequency gain $\mathrm{b}_{0}$. These two are the essential parameters for the ADRC design.

\section{STEP2: Observer Gains}

The state space model of plant represented as follows $\mathrm{sX}(\mathrm{s})=\mathrm{AX}(\mathrm{s})+\mathrm{BU}(\mathrm{s})+\mathrm{E}(\mathrm{s}) \mathrm{D}(\mathrm{s})$

\section{$\mathrm{Y}(\mathrm{s})=\mathrm{CX}(\mathrm{s})$}

$$
\begin{gathered}
\text { where } \mathrm{X}(\mathrm{s})=\left[\begin{array}{c}
\mathrm{X}_{1}(\mathrm{~s}) \\
\mathrm{X}_{2}(\mathrm{~s}) \\
\vdots \\
\mathrm{X}_{\mathrm{n}-\mathrm{m}}(\mathrm{s})
\end{array}\right]_{(\mathrm{n}-\mathrm{m})} ; \\
A=\left[\begin{array}{ccccc}
0 & 1 & 0 & \ldots & 0 \\
0 & 0 & 1 & \ldots & 0 \\
\vdots & \vdots & \vdots & \vdots & \vdots \\
0 & 0 & 0 & \ldots & 1 \\
0 & 0 & 0 & 0 & 0
\end{array}\right]_{(n-m) *(n-m)} ; B=\left[\begin{array}{c}
0 \\
0 \\
\vdots \\
b_{o} \\
0
\end{array}\right]_{(n-m)} \\
C=\left[\begin{array}{lllll}
1 & 0 & \ldots & \ldots & 0
\end{array}\right]_{(n-m)} ; E=\left[\begin{array}{c}
0 \\
0 \\
\vdots \\
\vdots \\
1
\end{array}\right]_{(n-m)}
\end{gathered}
$$

In order to derive the estimator, a state space model of the disturbed process can be represented as follows.

$s Z(s)=A Z(s)+B U(s)+L(Y(s)-\hat{Y}(s))$

where

$$
\hat{Y}(s)=C Z(s)
$$

$Z(s)=\hat{X}(s)=\left[Z_{1}(s) Z_{2}(s) \ldots . Z_{n-m}(s)\right]_{(n-m)}^{T}$ and

$L=\left[l_{1} l_{2} \ldots l_{n-m}\right]_{(n-m)}^{T}$.
To locate the all eigenvalues of the ESO to $-\omega_{o}$ (observer bandwidth), the observer gains are chosen as

$l_{i}=\left(\begin{array}{c}n-m+1 \\ i\end{array}\right) \cdot \omega_{o}^{i}, i=1,2, \ldots, n-m+1$.

By proper designing of ESO, $Z_{i}(s)$ will be estimating the values of $X_{i}(s)$ closely $(\mathrm{i}=1,2 \ldots \mathrm{n}-\mathrm{m})$. Then $Z_{n-m}=$ $\widehat{D}(s) \approx D(s)$. A well tuned ESO outputs $\hat{x}_{i}$ will track $x_{i}$ closely. Then

$\hat{x}_{n+1} \approx x_{n+1}=D$.

The generalized disturbance $d(t)$ can be removed by the time domain estimated value $x_{n+1}$

Now the control law $U(s)=\frac{U_{o}(s)-Z_{n-m}(s)}{b_{o}}$

And the system is reduced to a pure integral plant by substituting

$$
\begin{array}{r}
s^{n-m} Y(s)=b_{o} \cdot \frac{U_{o}(s)-Z_{n-m}(s)}{b_{o}}+D(s) \\
=U_{o}(s)-\widehat{D}(s)+D(s) \approx U_{o}(s)
\end{array}
$$

\section{Step 3: Controller Gains}

The control law for the pure integral plant is $U_{o}(s)=K_{1}\left(R(s)-Z_{1}(s)\right)-K_{2} Z_{2}(s)-\cdots-K_{n-m-1} Z_{n-m-1}(s)$

To simplify the tuning process, all the closed-loop poles of the controller are set to $-\omega_{c} . \omega_{c}$ represents the bandwidth of the controller. The controller gains have to be selected as

$$
k_{i}=\left(\begin{array}{c}
n-m \\
n-m-i+1
\end{array}\right) \omega_{c}^{n-m-i+1}, i=1,2, \ldots, n-m .
$$

Placing all the observer poles at one location is known as Bandwidth Parameterization. Increasing $\omega_{\mathrm{c}}$ the tracking speed of the output of ADRC controlled system will increase. In other words the tracking error, overshoot and settling time of the output will decrease. Generally, $\omega_{\mathrm{c}}$ varies from $3 \sim 10 \mathrm{rad} / \mathrm{s}$. The structure of control loop is presented in Fig. 6. On the whole design of ADRC may be accomplished from equations (7) (12), (14) and (15)

The proposed ADRC control for decentralized system is shown in Fig 2. In this figure an ADRC is placed in each area acting as a local LFC under decentralized control strategy. These two decentralized areas are connected through a tie line. The detailed structure of ADRC is given

in Fig 6. For this $\mathrm{LFC}$ problem, $\mathrm{ACE}_{1}$ and $\mathrm{ACE}_{2}$ are the reference inputs and load changes $\triangle \mathrm{PL}_{1}$ and $\triangle \mathrm{PL}_{2}$ are the external disturbances in areas 1 and 2 respectively.

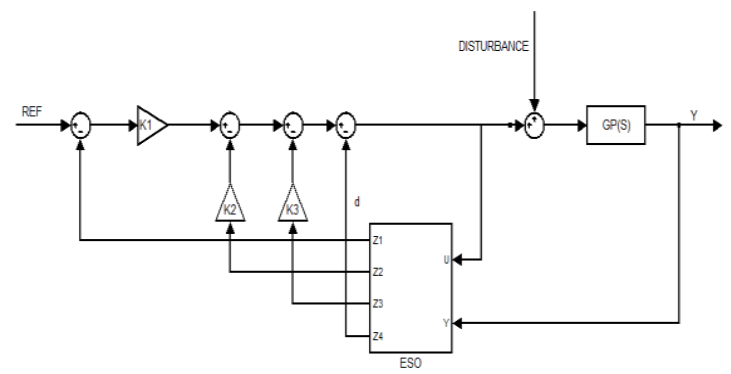

Fig 6 ADRC structure with state feedback 
The transfer function of primary loop of area 1 is

$$
\begin{aligned}
& G_{P}(s) \\
& =\frac{0.54 S^{2}+2.9 S+1}{1.544 S^{5}+21.92 S^{4}+105.3284 S^{3}+177.572 S^{2}+103.96 S+27}
\end{aligned}
$$

Here $\mathrm{n}=5, \mathrm{~m}=2, \mathrm{n}-\mathrm{m}=3, b_{3}=0.54, a_{6}=1.544$.

Hence $\mathrm{b}_{0}=b_{3} / a_{6}=2.85185$.

From (7), controller design equation

$s^{3} \mathrm{Y}(\mathrm{s})=2.85185 \mathrm{U}(\mathrm{s})+\mathrm{D}(\mathrm{s})$

The model of ESO is obtained as:

$$
\begin{aligned}
& \left(\begin{array}{c}
\dot{\mathrm{x}} 1 \\
\dot{\mathrm{x}} 2 \\
\dot{\mathrm{x}} 3 \\
\dot{\mathrm{x}} 4
\end{array}\right)=\left(\begin{array}{llll}
0 & 1 & 0 & 0 \\
0 & 0 & 1 & 0 \\
0 & 0 & 0 & 1 \\
0 & 0 & 0 & 0
\end{array}\right)\left(\begin{array}{l}
x 1 \\
x 2 \\
x 3 \\
x 4
\end{array}\right)+\left(\begin{array}{c}
0 \\
0 \\
2.85185 \\
0
\end{array}\right) \mathrm{u}+\left(\begin{array}{l}
0 \\
0 \\
0 \\
1
\end{array}\right) \dot{d} \\
& \mathrm{y}=\left(\begin{array}{llll}
1 & 0 & 0 & 0
\end{array}\right)\left(\begin{array}{l}
x 1 \\
x 2 \\
x 3 \\
x 4
\end{array}\right)
\end{aligned}
$$

From (10), (11) and (12) ESO may be written in terms of observer gains as

$$
\left(\begin{array}{c}
\dot{\hat{\mathrm{x}}} 1 \\
\hat{\hat{\mathrm{x}}} 2 \\
\hat{\hat{\mathrm{x}}} 3 \\
\dot{\hat{\mathrm{x}}} 4
\end{array}\right)=\left(\begin{array}{llll}
0 & 1 & 0 & 0 \\
0 & 0 & 1 & 0 \\
0 & 0 & 0 & 1 \\
0 & 0 & 0 & 0
\end{array}\right)\left(\begin{array}{l}
\hat{\mathrm{x}} 1 \\
\hat{\mathrm{x}} 2 \\
\hat{\mathrm{x}} 3 \\
\hat{\mathrm{x}} 4
\end{array}\right)+\left(\begin{array}{c}
0 \\
0 \\
2.85185 \\
0
\end{array}\right) \mathrm{u}(\mathrm{t})+\left(\begin{array}{c}
80 \\
2400 \\
32000 \\
160000
\end{array}\right)(\mathrm{y}-\hat{y})
$$

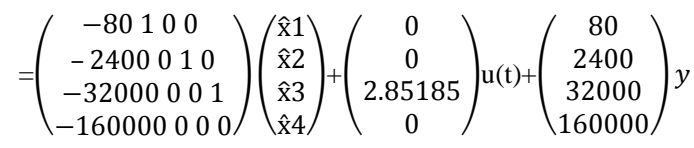

The ESO is derived for observer bandwidth $\omega_{0}=20 \mathrm{rad} / \mathrm{s}$. Next controller gains are computed from (15) for controller bandwidth $\omega_{c}=10 \mathrm{rad} / \mathrm{s}$, as

$$
k_{1}=1000, k_{2}=300, k_{3}=30 \text {. }
$$

Similarly for area 2 :

The transfer function of primary loop of area 2 is

$\mathrm{G}_{\mathrm{P}}(\mathrm{s})$

$$
=\frac{0.54 s^{2}+2.9 s+1}{1.624 S s^{5}+23.09 s^{4}+110.6 \mathrm{~s}^{3}+186.1 \mathrm{~s}^{2}+104.84 \mathrm{~s}+27}
$$

Here $\mathrm{n}=5, \mathrm{~m}=2, \mathrm{n}-\mathrm{m}=3, b_{3}=0.54, a_{6}=1.624$.

Hence $\mathrm{b}_{0}=b_{3} / a_{6}=0.3325$.

Observer Gains: $1_{1}=80 ; 1_{2}=2400 ; 1_{3}=32000 ; 1_{4}=160000$.

Controller Gains: $k_{1}=1000 ; k_{2}=300 ; k_{3}=30$.

\section{SIMULATION RESULTS}

The SIMULINK model of a two area PHEV based smart grid with V2G control and wind power generation is shown in Fig. 2. The controllers in areas 1 and 2 are either PID or ADRC controllers based on the case. Here the system analysis is carried out as two cases. In case 1 analysis of the system is performed with step change in load and without wind power generation. The results are shown in figures 7- 9. In case 2 analysis is executed including random wind power generation and random load. These results are shown in figures 10-21.

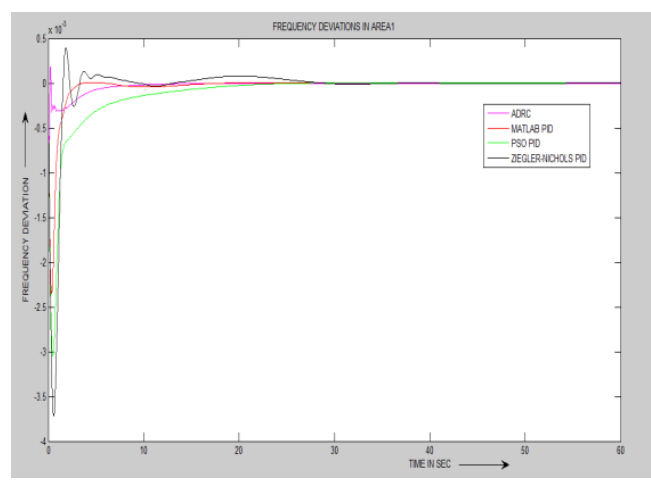

Fig. 7- Frequency Deviations in Area 1

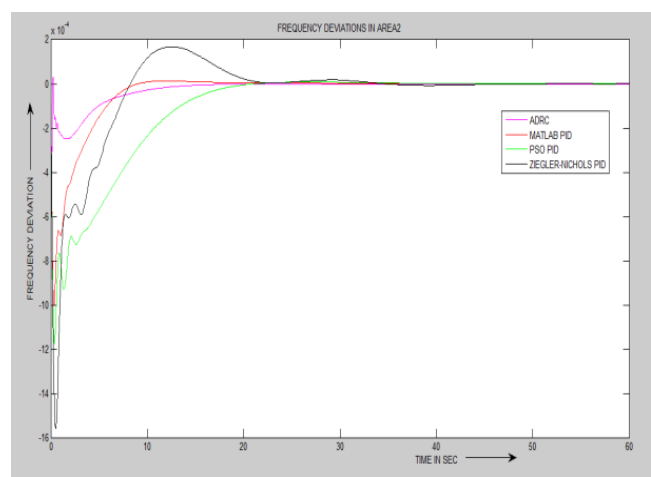

Fig.8-Frequency Deviations in Area 2

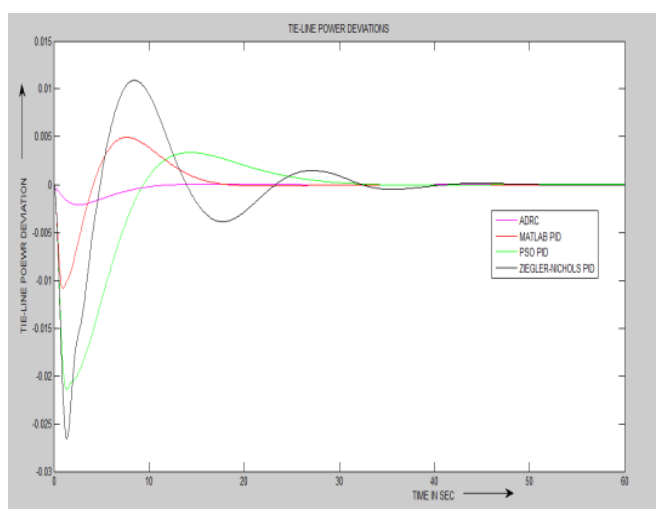

Fig.9-Tie-Line Power Deviations 


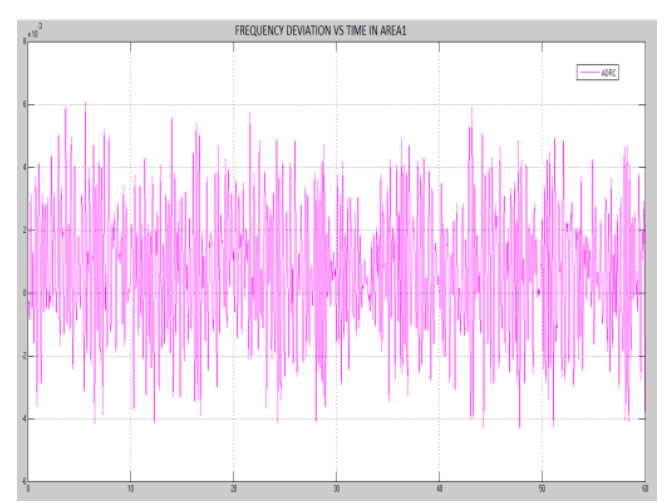

Fig.10- Frequency Deviations in Area 1

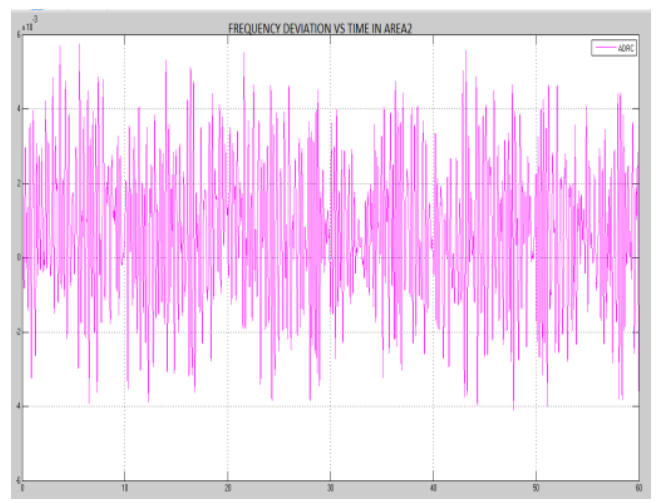

Fig.11-Frequency Deviations in Area 2

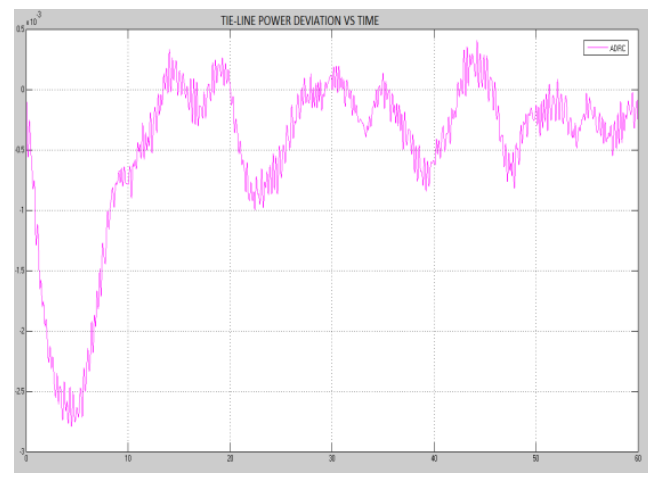

Fig.12-Tie-Line Power Deviations

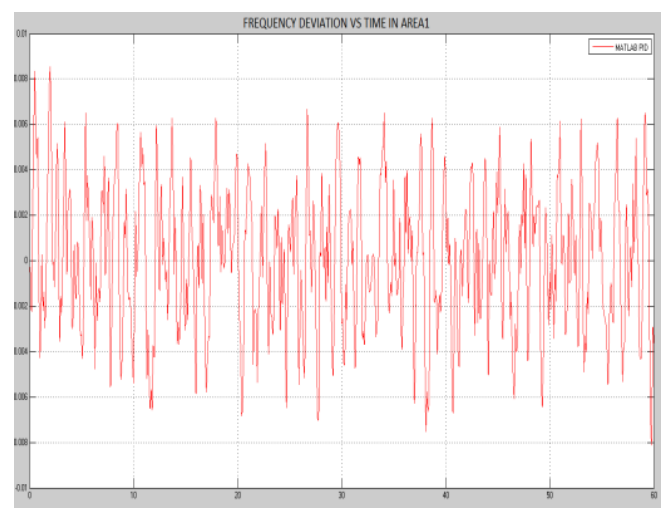

Fig.13- Frequency Deviations in Area 1

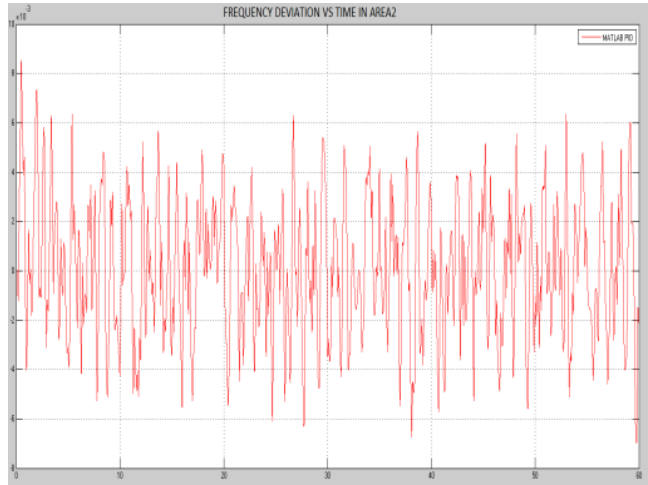

Fig.14- Frequency Deviations in Area 2

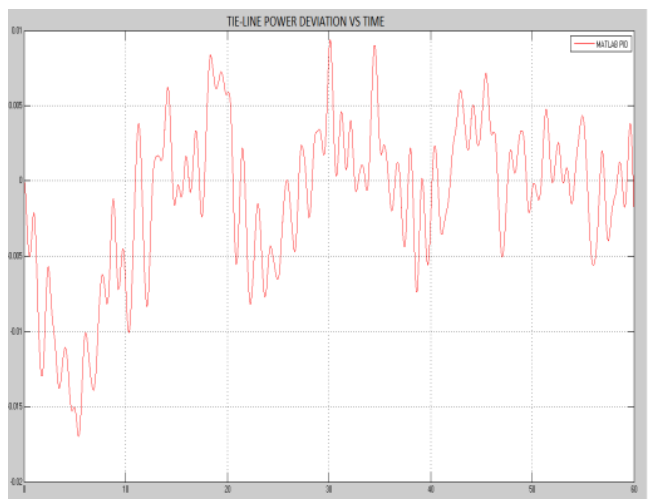

Fig.15-Tie-Line Power Deviations

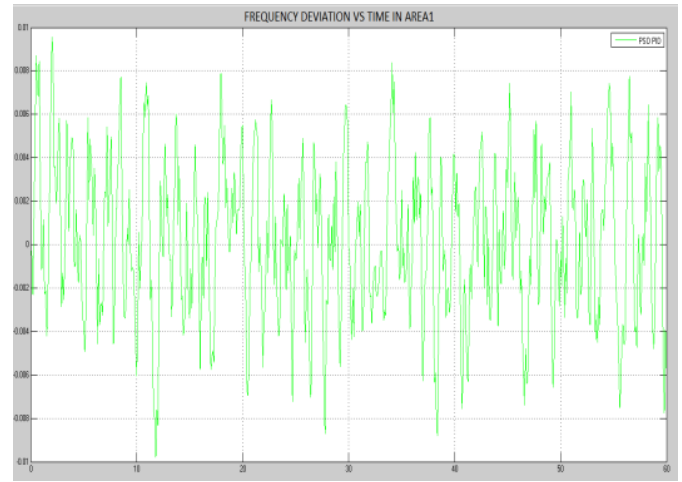

Fig.16- Frequency Deviations in Area 1

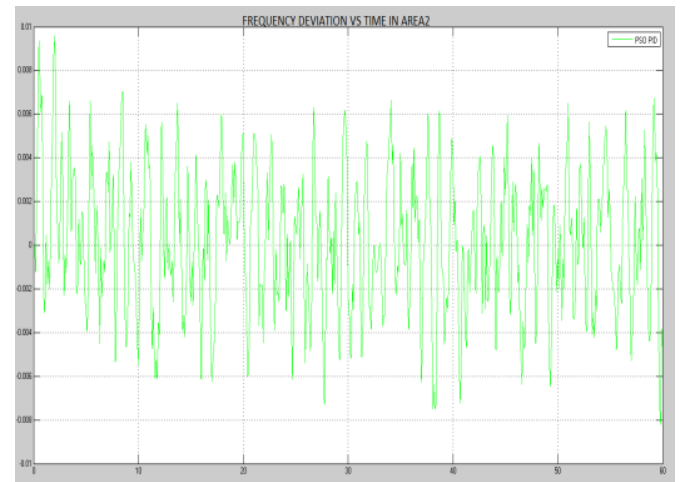

Fig.17- Frequency Deviations in Area 2 


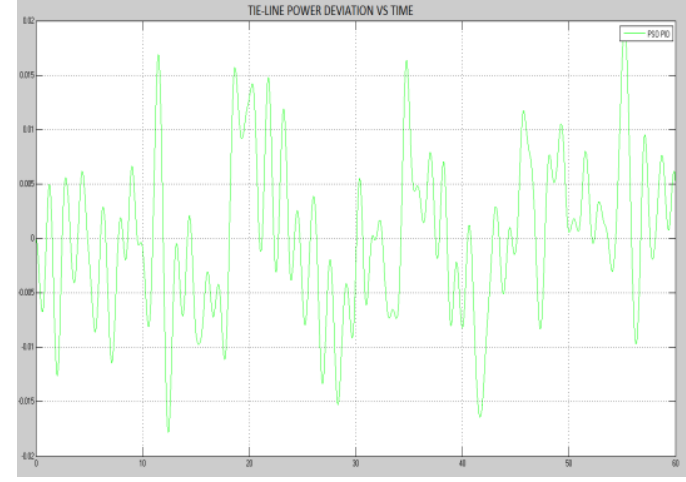

Fig.18-Tie-Line Power Deviations

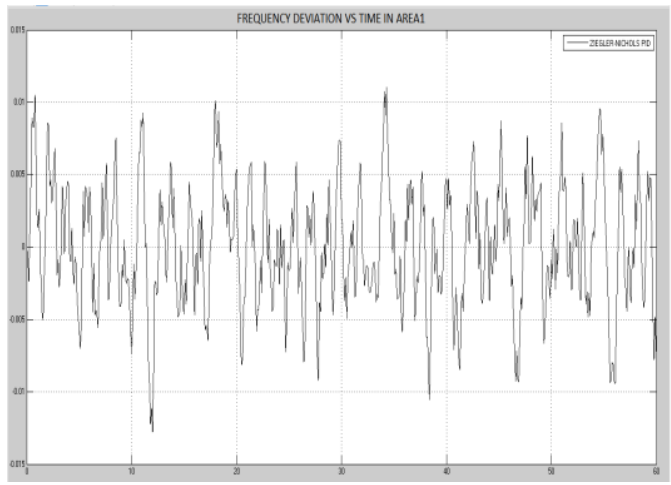

Fig.19- Frequency Deviations in Area 1

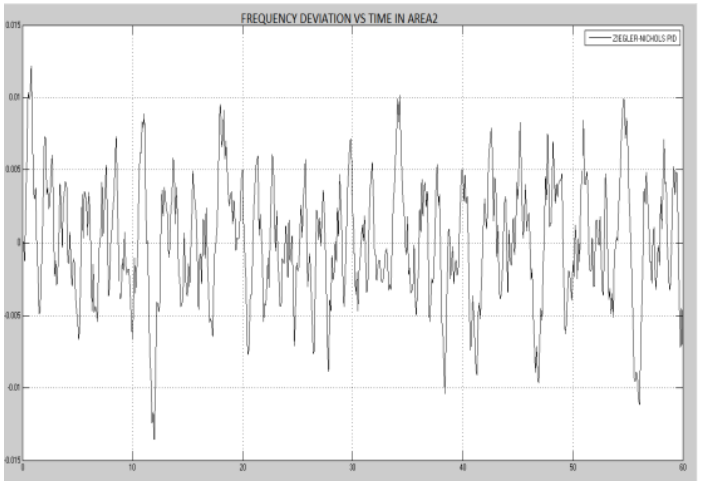

Fig.20- Frequency Deviations in Area 2

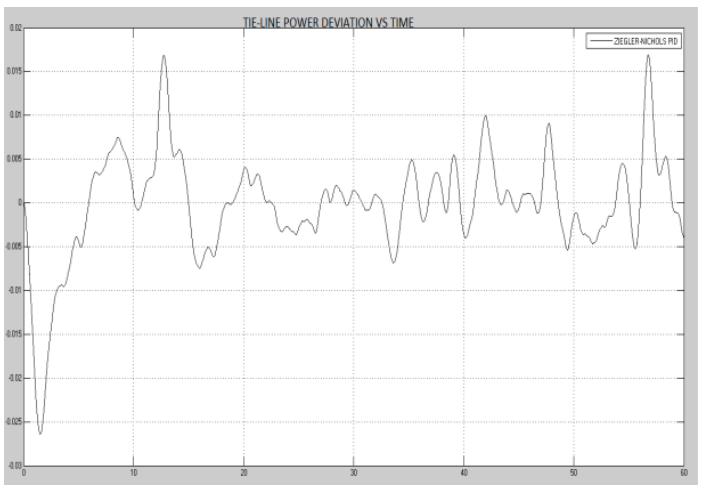

Fig.21-Tie-Line Power Deviations

\section{CONCLUSIONS}

Recent trend in power system operation is smart grid. Accordingly an attempt is made to provide a better controller for two-area smart grid power systems. It is studied as two cases. Incase 1, the behavior of two-area PHEV based smart grid with V2G Control without wind power generation with PID controller tuned by Z-N, PSO, MATLAB methods and ADRC controller is studied. Next as case 2, the behavior of two-area smart grid with PHEV includingV2G Control and random wind power generation and random load with PID and ADRC controllers as mentioned above is analyzed. From the figures7-21it can be concluded that ADRC controller is the best with good transient and steady state responses closely followed by MATLAB tuned PID controller in both cases. Further this work may be extended to multi-area smart power grids with robust control as future extension.

\section{ACKNOWLEDGMENTS}

We greatly acknowledge Siddhartha Academy of General and Technical Education, Vijayawada for providing the facilities to carry out this research.

\section{REFERENCES}

[1] Hadi Saadat, Power System Analysis, Tata McGraw-Hill, New Delhi, 2007

[2] Elgerd Ol. Electric energy system theory: an introduction. 2/e. McGraw Hill, New York:,1983.

[3] Kundur P. Power system stability and control. 5th reprint. Tata McGraw Hill; New Delhi: 2008.

[4] Kothari DP, Nagrath IJ. Modern power system analysis.4/e. New Delhi: Tata McGraw Hill; 2011.

[5] Ibraheem, Kumar P, Kothari DP. Recent philosophies of automatic generation control strategies in power systems. IEEE Trans Power Syst 2005;20(1):346-57.

[6] U.S. Department of Energy (DOE), "Smart grid system report," Jul.2009 [Online]. Available: http://www.oe.energy.gov/DocumentsandMedia/SGSRMain_090707_lowres.pdf

[7] Y. Ota et al., "Effect of autonomous distributed vehicle-togrid (V2G)on power system frequency control," in Proc. Int. Conf. Ind. Inf. Syst.(ICIIS), pp. 481-485.

[8] K. Shimizu et al., "Load frequency control in power system using vehicle-to-grid system considering the customer convenience of electric vehicles," in Proc. Int. Conf. 2010 Power Syst. Technol. (POWERCON),pp. 1-8.

[9] S. W. Hadley and A. Tsvetkova, "Potential impacts of plug-in hybrid electric vehicles on regional power generation," Oak Ridge National Laboratory, Oak Ridge, TN, ORNL/TM-2007/150, Jan. 2008.

[10] J. R. Pillai and B. Bak-Jensen, "Integration of vehicle-togrid in the Western Danish power system," IEEE Trans. Sustainable Energy, vol.2, no. 1, pp. 12-19, Jan. 2011.

[11] Sitthidet Vachirasricirikul and Issarachai Nigamroo "Robust LFC in a Smart Grid with Wind PowerPenetration by Coordinated V2G Control andFrequency Controller", IEEE Trans. Smart Grid, vol. 5, no. 1, pp.371-380, Jan 2014 
[12] Y. Ota, H. Taniguchi, T. Nakajima, K. M. Liyanage, J. Baba, and A.Yokoyama, "Autonomous distributed V2G (vehicle-to-grid) satisfyingscheduled charging," IEEE Trans. Smart Grid, vol. 3, no. 1, pp.559-564, Mar. 2012

[13] Kennedy, J., Eberhart, R.C., Particles Swarm Optimization, Proc. IEEE International Conferenceon Neural Networks, Perth Australia, IEEE ServiceCenter, Piscataway, NJ, IV: 1942-1948, 1995.

[14] Han, J., "From PID to active disturbance rejection control", IEEE Trans. Ind. Electron, 2009, 56, 900-906.

[15] Jingqing Han, "Auto-disturbances-rejection Controller and It's Applications", Control And Decision, Vol 13,No.1, pp.19-23,Jan.1998.

[16] Zheng Qing and GAO Zhiqiang, "On Practical Applications of Active Disturbance Rejection Control",
Proceedings of the $29^{\text {th }}$ Chinese Control Conference July 29-31, 2010, Beijing, China.

[17] Krishnarayalu M.S. and K. Nagarjuna "AVR with ADRC “, International Electrical Engineering Journal (IEEJ) Vol. 5 (2014) No.8, pp. 1513-1518, ISSN 20782365

[18] Krishnarayalu M.S. and K. Nagarjuna "ADRC for TwoArea LFC" , IJERT, ISSN: 2278-0181,Vol. 3 Issue 11, November - 2014, pp 141-146

[19] M.Nagendra and M.S.Krishnarayalu. "PID Controller Tuning using Simulink for Multi Area Power Systems", IJERT, Vol. 1 Issue 7, September - 2012

[20] Katsuhiko Ogata, Modern Control Engineering, 5/e PHI, New Delhi, 2010. 